\title{
Introduction to Organizational Learning Minitrack
}

\author{
Julee Hafner \\ The Chicago School Of Professional Psychology \\ haf2lead@gmail.com
}

\begin{abstract}
Welcome to this, the 51st anniversary of the Hawaii International Conference on System Sciences (HICSS) conferences. This is the third year of the Organizational Learning Minitrack, proudly bringing you the latest research focused on knowledge management issues for organizational learning.

Organizations that consider themselves "learning" or "knowledge-based" need to better understand how to develop their workforce using organizational learning. The focus on new techniques and insights into how individuals and organizations use knowledge will add to the body of research in knowledge management (KM). This minitrack is devoted researching these issues for the improvement of organizational learning.
\end{abstract}

\section{Introduction}

The ability or lack of the ability to change and use knowledge effectively, especially in light of the knowledge explosion, can be costly for today's organizations. There is a gap in the knowledge between the current learning of organizations and their ability to create, acquire, transfer and manage knowledge for a variety of processes. Organizations that consider themselves "learning" or "knowledge-based" want to structure their knowledge intra-organizationally and inter-organizationally to implement technology, maximize outcomes, and create competitive within the marketplace.

Organizational learning involves the processes of creating, transferring, modifying and retaining knowledge over time. These learning processes may occur at the individual, group or organizational levels and involve developing and benefitting essential functions within the organization.
This mini-track examines research into these organizations and their workers to understand the how to use learning, knowledge management, and behavioral strategies for success.

\section{Giannakos, Mikalef, and Pappas}

Our first presenters are Michail Giannakos, Patrick Mikalef, and Ilias Pappas who will present a paper entitled: Influence of Data Analysis, Entrepreneurial and Business Skills on Information Technology Firms: A Dynamic Capabilities Approach.

In the current business environment, innovation and quality of Information Technology (IT) products and services depend to a great extent on the knowledge, ability and talent applied by IT professionals. These IT professionals require integration, development, and reconfiguration of resources to continuously evolve these products and services for the changing marketplace.

When inefficiencies occur, it usually comes from the IT professionals' inability to apply skills in a way that allows for adaptation and evolution concurrently with business demands. 72 IT professionals tested the importance that data analytics, entrepreneurial, and business skills have in enhancing employees' dynamic capabilities and ultimately their perceived work performance. By fostering capacity between the three types of skills and employees' ability to effectuate action a firm can evolve.

\section{Freeze and Bristow}

Our next presenters will be Ronald Freeze and Susan Bristow who will present ERP Knowledge: Enhancing Program Growth for Workforce Impact. Enterprise Resource Planning (ERP) systems 
foundationally enable organizations to perform day-today operations in an integrated, efficient, and compliant manner. ERP systems are robust, come with complexity needing a significant learning curve for the entire organization, and require workforce talent that understands these systems. This study initiates a longitudinal analysis that focuses on the ERP program's knowledge map development to measure workforce knowledge. Business knowledge and business knowledge gaps of ERP concepts can improve the pace of the knowledge map development and be refined with course/program progression.

\section{Pflügler, Malzer, Jäschke, Wiesche, Krcmar and Mützel}

Our third presenters are, Christoph Pflügler, Thorsten Malzer, Tamara Jäschke, Manuel Wiesche, Helmut Krcmar and Markus Mützel. They will discuss their submission, Do I Want to Have "Losers" In My Team? - A Quantitative Study of Learning from IT Project Failure.

There is a lack of current research related to the learning from failed IT projects of IT professionals. Whether professionals are able to use their experiences to conduct projects that are more successful in the future is in question. Can IT professionals learn from failed projects? Can they leverage this experiential knowledge to enhance future projects? The authors investigate this issue using a large quantitative dataset from a German IT service provider company. This first of its kind research, contributes to the understanding of and related to learning from failure in IT literature.

\section{Gupta and Bose}

Our fourth and final presenters, Gaurav Gupta and Indranil Bose will discuss their research entitled: Transforming temporary organizations to permanence: Examining the role of information systems.

Temporary organizations may transform into permanent ones over time. Information systems are pivotal to such organizational transformation. An exploratory case study will be used to examine how information systems in a disaster management firm can undergo rapid change and drive such transformation. The authors propose a dynamic framework for examining the process of transformation across different phases of the process. Information systems hold significant influence on communication, coordination, and control of various teams in temporary organizations. This study helps develop a vocabulary for future research on transformation for such temporary organizations.

\section{Conclusion}

We wish to thank each of our presenters for their research efforts. I am sure that their willingness to share their study results will help to develop this unique minitrack and contribute to the ongoing development of organizational issues. I personally welcome each of the attendees and thank them for great discussions during another year of celebration at HICSS-51. We look forward seeing new and ongoing research in the field of Organizational Learning. I hope all authors attending will consider contributing to our mini-track, Organizational Learning, next year. 